\title{
Ni/KIT-6 catalysts for hydrogenolysis of lignin-derived diphenyl ether
}

\author{
JYOTHI YADAGIRI ${ }^{\mathrm{a}, \mathrm{b}, *}$, KUMARA SWAMY KOPPADI $^{\mathrm{a}}$, SIVA SANKAR ENUMULA ${ }^{\mathrm{a}}$, \\ VENKATESHWARLU VAKATI ${ }^{a}$, SEETHA RAMA RAO KAMARAJU ${ }^{a}$, DAVID RAJU BURRI ${ }^{a}$ \\ and PUPPALA VEERA SOMAIAH ${ }^{\mathrm{b}, *}$ \\ ${ }^{a}$ Catalysis Laboratory, CSIR- Indian Institute of Chemical Technology, Uppal Road, Hyderabad 500 607, India \\ ${ }^{b}$ Department of Chemistry, University College of Science, Osmania University, Hyderabad 500 007, India \\ E-mail: jyothichemou@gmail.com; profvspuppala@gmail.com
}

MS received 13 March 2018; revised 23 May 2018; accepted 3 June 2018; published online 24 July 2018

\begin{abstract}
A series of mesoporous silica KIT-6 supported Ni catalysts were prepared by wet impregnation method and evaluated for the lignin-derived diphenyl ether hydrogenolysis under atmospheric pressure in the continuous process. All the catalysts were characterized by powder XRD, $\mathrm{N}_{2}$-physisorption, SEM, TEM, $\mathrm{H}_{2}$ TPR analysis $\mathrm{H}_{2}$-pulse chemisorption studies. Among the catalysts, 20-wt\%-Ni/KIT-6 exhibited better activity and selectivity due to the well dispersion of Ni particles through uniform pore channel of KIT-6. 20Ni/KIT-6 shows consistent selectivity to aromatics with a decrease in conversion of diphenyl ether during the time on stream studies.
\end{abstract}

Keywords. KIT-6; nickel; hydrogenolysis; lignin; diphenyl ether.

\section{Introduction}

The ever-increasing consumption of non-renewable sources results in a search for alternative sources of energy. During this quest for sustainable production of chemicals, lignocellulosic biomass has evolved as a renewable source for the production of chemicals and fuels. The cellulosic part (65-85\% by weight) with simple chemical structures can be upgraded into chemicals via a series of reactions. However, an efficient conversion of complex structured lignin (15-30\% by weight) is a challenging one. ${ }^{1,2}$ The pyrolysis of lignin leads to the formation of highly viscous bio-oil which has low heating value, thermal instability and is complicated to utilize. $^{3}$ An alternative approach to convert lignin in an efficient way is its reductive depolymerization. Lignin is a network polymer consisting of phenylpropane units that are connected via $\mathrm{C}-\mathrm{C}$ and/or $\mathrm{C}-\mathrm{O}-\mathrm{C}$ linkages; among them more than $80 \%$ linkages are ether linkages. Most of the phenylpropane units are connected through $\alpha-\mathrm{O}-4, \beta-\mathrm{O}-4,4-\mathrm{O}-5$ linkages and their bond dissociation energies are in the order of $\alpha-\mathrm{O}-4<\beta-$ O-4 $<4-\mathrm{O}-5\left(\sim 314 \mathrm{~kJ} \mathrm{~mol}^{-1}\right) .{ }^{4,5}$ The cleavage of the strongest $4-\mathrm{O}-5$ ether bond $\left(\mathrm{C}_{\text {aryl }}-\mathrm{O}-\mathrm{C}_{\text {aryl }}\right)$ of lignin is one of the choices for productive depolymerization.

\footnotetext{
${ }^{*}$ For correspondence
}

The cleavage of $\mathrm{C}_{\text {aryl }}-\mathrm{O}-\mathrm{C}_{\text {aryl }}$ linkage of lignin results in the production of phenols and arenes which makes lignin a sustainable source for aromatic compounds. The cleavage of $\mathrm{C}_{\text {aryl }}-\mathrm{O}-\mathrm{C}_{\text {aryl }}$ linkage can be achieved by hydrolysis or hydrogenolysis reactions. In order to investigate the cleavage of $\mathrm{C}_{\text {aryl }}-\mathrm{O}-\mathrm{C}_{\text {aryl }}$ bond, Diphenyl ether (DPE) has been selected as a model compound. It is a difficult task to cleave the $\mathrm{C}-\mathrm{O}$ bond with high dissociation energy $\left(\sim 218\right.$ to $314 \mathrm{~kJ} \mathrm{~mol}^{-1}$ ) without disturbing aromatic rings. Many researchers have examined noble and non-noble metal catalytic systems for hydrogenolysis/hydrodeoxygenation (HDO) of lignin model compounds related to the lignin up gradation. Several noble metal catalytic systems such as supported $\mathrm{Ru}, \mathrm{Pd}, \mathrm{Pt}, \mathrm{Rh}$ catalysts and non-noble catalytic systems supported $\mathrm{Cu}, \mathrm{Co}, \mathrm{Ni}$ catalysts are reported. ${ }^{6-10}$ Among those catalytic systems Ni-based catalysts are more prominent and inexpensive compared to other noble metal catalysts in reductive depolymerization of lignin. Sergeev et al., examined $\mathrm{Ni}(\mathrm{COD})_{2}$ complex for cleavage of DPE m-xylene as solvent. ${ }^{11}$ Fang et al., studied chemo- and region-selective hydrogenolysis of $\mathrm{C}-\mathrm{O}$ bonds over $\mathrm{Ni} / \mathrm{C}$ and found that embedded stable metal nanoparticles could cleave aryl ether linkages even in substituted diaryl ethers. ${ }^{12} \mathrm{He}$ et al., investigated aqueous phase cleavage of aryl ethers by $\mathrm{Ni} / \mathrm{SiO}_{2}$ 
catalyst and reported that simultaneous hydrogenolysis and hydrolysis reactions occur during the cleavage. ${ }^{13}$ The same group has reported mechanistic aspects of aqueous phase cleavage of the aryl ethers and has also studied the influence of substitution. ${ }^{14}$ Wang et al., have explored Raney $\mathrm{Ni}$ as a catalyst for hydrogenolysis of DPE along with the specific role of solvents. The basicity of solvent has profound influence on product selectivity in hydrogenolysis of DPE. ${ }^{15}$ In view of the excellence of Ni catalysts in the hydrogenolysis of DPE, the present study was undertaken to develop mesoporous silica (KIT-6)-supported Ni catalysts for hydrogenolysis of lignin model compounds. The application of mesoporous silica as support offers high surface area, uniform pore channels to accommodate active species, hydrophobic nature and high thermal stability. ${ }^{16,17}$ Here in we report hydrogenolysis of DPE over Ni/KIT-6 catalysts in continuous process at atmospheric $\mathrm{H}_{2}$.

\section{Experimental}

\subsection{Catalyst preparation}

Mesoporous silica (KIT-6) was synthesized by following a reported procedure. ${ }^{18}$ In a typical synthesis, a mixture of $4.0 \mathrm{~g}$ of P123 (M/s. Sigma-Aldrich, USA) and $7.9 \mathrm{~g}$ of $35-\mathrm{wt} \%$ $\mathrm{HCl}$ in $144 \mathrm{~g}$ of deionized water was stirred for $8 \mathrm{~h}$ at $35^{\circ} \mathrm{C}$ and then $4 \mathrm{~g}$ of 1-butanol was added and stirred for $1 \mathrm{~h}$ at $35^{\circ} \mathrm{C}$. To this solution, $8.6 \mathrm{~g}$ of TEOS (M/s. Sigma-Aldrich, USA) was added dropwise and continuously stirred for $24 \mathrm{~h}$. The resultant solution has undergone static hydrothermal ageing at $100^{\circ} \mathrm{C}$ for $24 \mathrm{~h}$ and washed with deionized water. The solid was kept in a hot oven at $100^{\circ} \mathrm{C}$ for $12 \mathrm{~h}$ and calcined at $550^{\circ} \mathrm{C}$ for $8 \mathrm{~h}$ inflow of air. The white solid mass was used as support (KIT-6). Ni/KIT-6 catalysts were prepared via simple wet impregnation method. For this method, the requisite amount of $\mathrm{Ni}\left(\mathrm{NO}_{3}\right)_{2} \cdot 6 \mathrm{H}_{2} \mathrm{O}$ as a nickel precursor dissolved in water was added to the KIT-6 support. The mixture was then allowed to complete dryness on a hot plate and dried in an oven at $100^{\circ} \mathrm{C}$ for $12 \mathrm{~h}$. Subsequently, calcined at $500^{\circ} \mathrm{C}$ for $5 \mathrm{~h}$ in air and denoted as XNK6 where $\mathrm{X}$ denotes weight percentage of $\mathrm{Ni}$ and $\mathrm{X}$ is equal to $15,20,25$ and 30.

\subsection{Catalyst characterization}

The X-ray diffraction patterns were recorded on an UltimaIV (M/s. Rigaku Corporation, Japan) operated at $40 \mathrm{kV}$ and $40 \mathrm{~mA}$ equipped with nickel-filtered $\mathrm{Cu} \mathrm{K} \alpha$ radiation $(\lambda=1.54056 \AA)$. The BET surface areas, pore volume and pore sizes were determined by using the $\mathrm{N}_{2}$ physisorptiondesorption studies (M/s. Quantachrome Instruments, USA, samples were degassed at $150{ }^{\circ} \mathrm{C}$ for $2 \mathrm{~h}$ ) by nitrogen adsorption at liquid $\mathrm{N}_{2}$ temperature. Temperature programmed reduction of hydrogen $\left(\mathrm{H}_{2}\right.$-TPR) was performed on a homemade TPR system. Typically, About $50 \mathrm{mg}$ of the catalyst was placed in a quartz reactor and pre-treated in Helium flow $\left(30 \mathrm{~mL} \mathrm{~min}{ }^{-1}\right.$ ) at $300{ }^{\circ} \mathrm{C}$ for $1 \mathrm{~h}$. Later, the catalyst was treated with $5 \% \mathrm{H}_{2}-\mathrm{Ar}$ mixture gas $\left(30 \mathrm{~mL} \mathrm{~min}^{-1}\right)$ while increasing the temperature up to $800{ }^{\circ} \mathrm{C}$ with a temperature ramp of $10{ }^{\circ} \mathrm{C} \mathrm{min}-1$ and it was monitored using a thermal conductivity detector. $\mathrm{H}_{2}$-pulse chemisorption studies were carried out on an Autosorb-iQ automated gas sorption analyser (Quantachrome Instruments, USA) at $40^{\circ} \mathrm{C}$. The catalyst was pre-reduced at $500{ }^{\circ} \mathrm{C}$ for $2 \mathrm{~h}$ and evacuated for $2 \mathrm{~h}$ to remove physisorbed hydrogen. The temperature is cooled down to $40{ }^{\circ} \mathrm{C}$ and $\mathrm{H}_{2}$ uptake was determined by injecting $\mathrm{H}_{2}(100 \mu \mathrm{l})$ in pulses subsequently. SEM images of the catalysts were recorded on a scanning electron microscope $(\mathrm{M} / \mathrm{s}$. JEOL, Switzerland) and TEM images were obtained on a JEM 2000EXII apparatus (M/s. JEOL, Switzerland) respectively. Prior to TEM analysis, the catalyst sample was ultrasonicated in ethanol and a drop was placed onto the carbon coated copper grid. The solvent was then dried in an air oven at $80^{\circ} \mathrm{C}$ for $6 \mathrm{~h}$.

\subsection{Activity studies}

The hydrogenolysis of DPE was conducted in a fixed bed downflow reactor (14 $\mathrm{mm}$ i.d. and $300 \mathrm{~mm}$ length) at atmospheric conditions. In a typical experiment, about $1 \mathrm{~g}$ of the catalyst was mixed with the same amount of quartz particles and sandwiched between two plugs at the centre of the reactor. Before the reaction, the catalyst was a reduced inflow of $\mathrm{H}_{2}$ $\left(30 \mathrm{~mL} \mathrm{~min}^{-1}\right)$ at $500^{\circ} \mathrm{C}$ for $4 \mathrm{~h}$ and then the reaction temperature is fixed. The liquid feed was fed into the reactor by using syringe feed pump (M/s. B. Braun, Germany). The product mixture collected periodically from an ice-cooled trap was analyzed by FID equipped GC-17A (M/s. Shimadzu Instruments, Japan) with EB-5 capillary column $(30 \mathrm{~m} \times 0.53 \mathrm{~mm}$ $\times 5.0 \mu \mathrm{m})$ and confirmed by GC-MS, QP-2010 (M/s. Shimadzu Instruments, Japan) with EB-5 MS capillary column $(30 \mathrm{~m} \times 0.25 \mathrm{~mm} \times 0.25 \mu \mathrm{m})$.

\section{Results and Discussion}

The low-angle XRD patterns of KIT-6 and NK6 catalysts were presented in Figure 1(a). It can be observed that all the NK6 catalysts show three diffraction peaks at $2 \theta$ around $0.92,1.62,1.89^{\circ}$ corresponds to the (211), (220) and (420) planes, respectively, which indicate the existence of 3D-cubic mesoporous structure of the parent KIT- 6 of Ia3d symmetry. ${ }^{18,19}$ The existence of mesoporous structure of KIT- 6 can be found even after deposition of highest amount (30 wt\%) of Ni. The wideangle XRD patterns of NK6 catalysts were shown in Figure 1(b). The broad diffraction peak at $2 \theta$ around 15 $30^{\circ}$ is representative for amorphous silica. All reduced NK6 catalysts show XRD reflections at $44.49^{\circ}(111)$, 

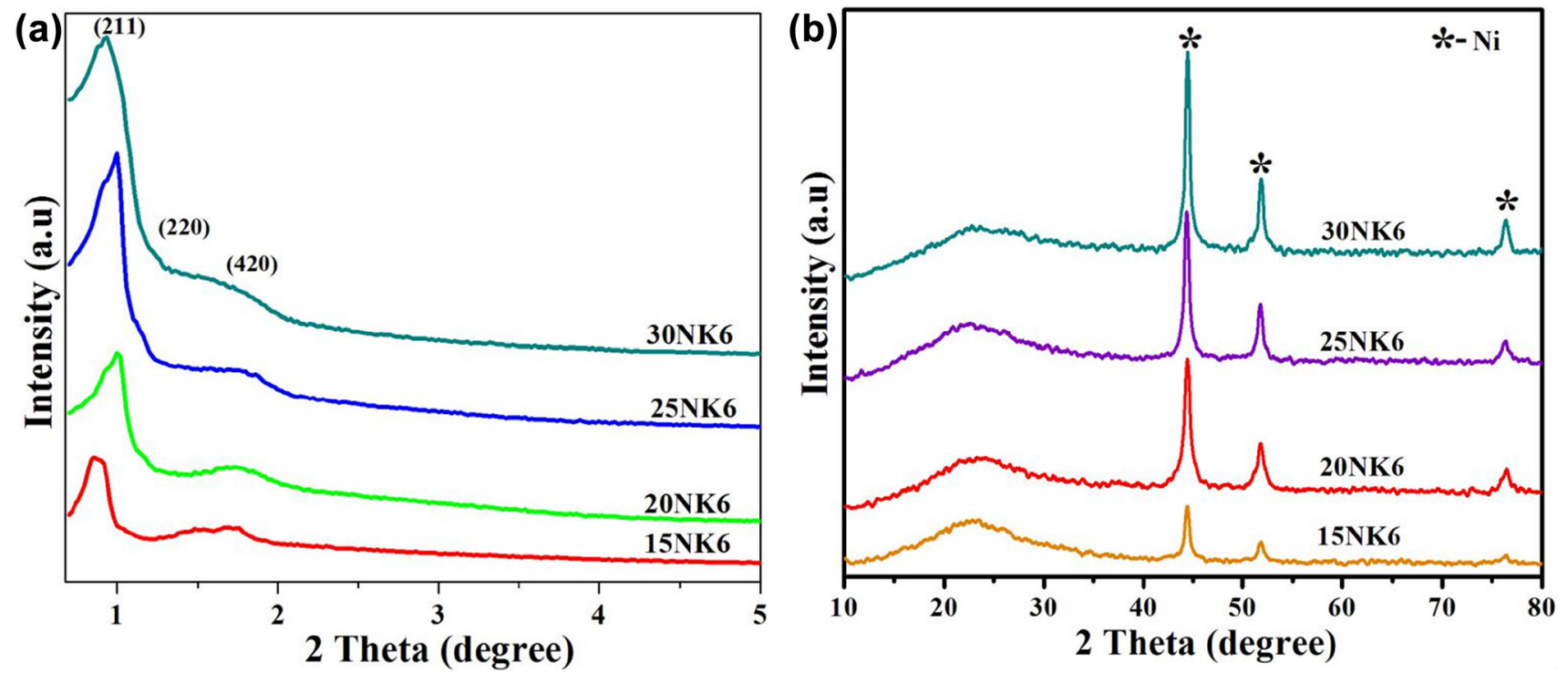

Figure 1. (a) Low-angle and (b) Wide angle XRD patterns of NK6 catalysts.

Table 1. Textural/structural parameters KIT-6 and various NK6 catalysts.

\begin{tabular}{lcccc}
\hline Catalysts & $\begin{array}{c}\text { Surface area } \\
\left(\mathrm{m}^{2} / \mathrm{g}\right)\end{array}$ & $\begin{array}{c}\text { Pore volume } \\
(\mathrm{cc} / \mathrm{g})\end{array}$ & $\begin{array}{c}\text { Pore diameter } \\
(\mathrm{nm})\end{array}$ & $\begin{array}{c}\text { Crystallite size } \\
(\mathrm{nm})\end{array}$ \\
\hline KIT-6 & 651 & 0.87 & 11.2 & - \\
$15 \mathrm{NK} 6$ & 394 & 0.62 & 8.7 & 15 \\
$20 \mathrm{NK} 6$ & 412 & 0.68 & 8.8 & 21 \\
25 NK6 & 335 & 0.53 & 8.7 & 29 \\
30NK6 & 331 & 0.51 & 8.7 & 35 \\
\hline
\end{tabular}

$51.85^{\circ}(200)$ and $76.38^{\circ}$ (220) corresponding to metallic $\mathrm{Ni}$ with a face-centered cubic geometry of space group Fm3m (225) (ICDD. No. 87-0712). The crystallite sizes of the catalysts are measured by using Debye-Scherrer formula from their full width at half maximum (FWHM) values and are presented in Table 1. It can be observed that the crystallite size of $\mathrm{Ni}$ is increasing with metal loading. However, the retention of mesoporous structure of KIT- 6 even after $30 \mathrm{wt} \%$ of Ni deposition shows that the high surface area KIT- 6 is more advantageous in dispersing the active metal.

Figure 2(a) shows $\mathrm{N}_{2}$ adsorption-desorption isotherms of NK6 samples. All the samples exhibit type $\mathrm{IV}$ isotherms with $\mathrm{H} 2$ hysteresis loop which is indicative of the presence of mesoporous structure with cage-like pores in accordance with the IUPAC classification and provide evidence to the retention of mesoporous structure. ${ }^{20}$ The decrease in height of the loops with an increase in the weight loading is due to the decrease in the pore volume. ${ }^{21}$ The structural and textural properties of the samples are presented in Table 1 . The surface area and pore volumes of the samples are decreasing with an increase in the metal content. This decrease might be due to higher density of nickel blocking the mesopores of KIT-6. The pore size distribution of Ni/KIT-6 samples obtained from adsorption shows bi-model pore size distribution with average pore sizes $5-9 \mathrm{~nm}$.

The morphological features of Ni/KIT-6 samples of fresh and spent catalysts were assessed by SEM and TEM techniques and corresponding images are presented in Figures 3 and 4, respectively. SEM image of fresh 20NK6 catalyst shows agglomerated squares and EDX spectrum which makes the presence and composition of Ni evident. From the EDX analysis, elemental composition is calculated for the fresh 20NK6 catalyst and it is found to be $\sim 21 \mathrm{wt} \%$ of Ni. TEM images display uniform pore channels and dispersed Ni particles through that channels. From XRD, $\mathrm{N}_{2}$-physisorption, SEM and TEM analysis, it could be confirmed that the mesoporous structure of KIT-6 is preserved and Ni particles are well-dispersed over a high surface area of KIT-6.

In order to investigate the metal support interactions, the location of the metal particles (inside the pores or on the surface) and reduction behavior of the 

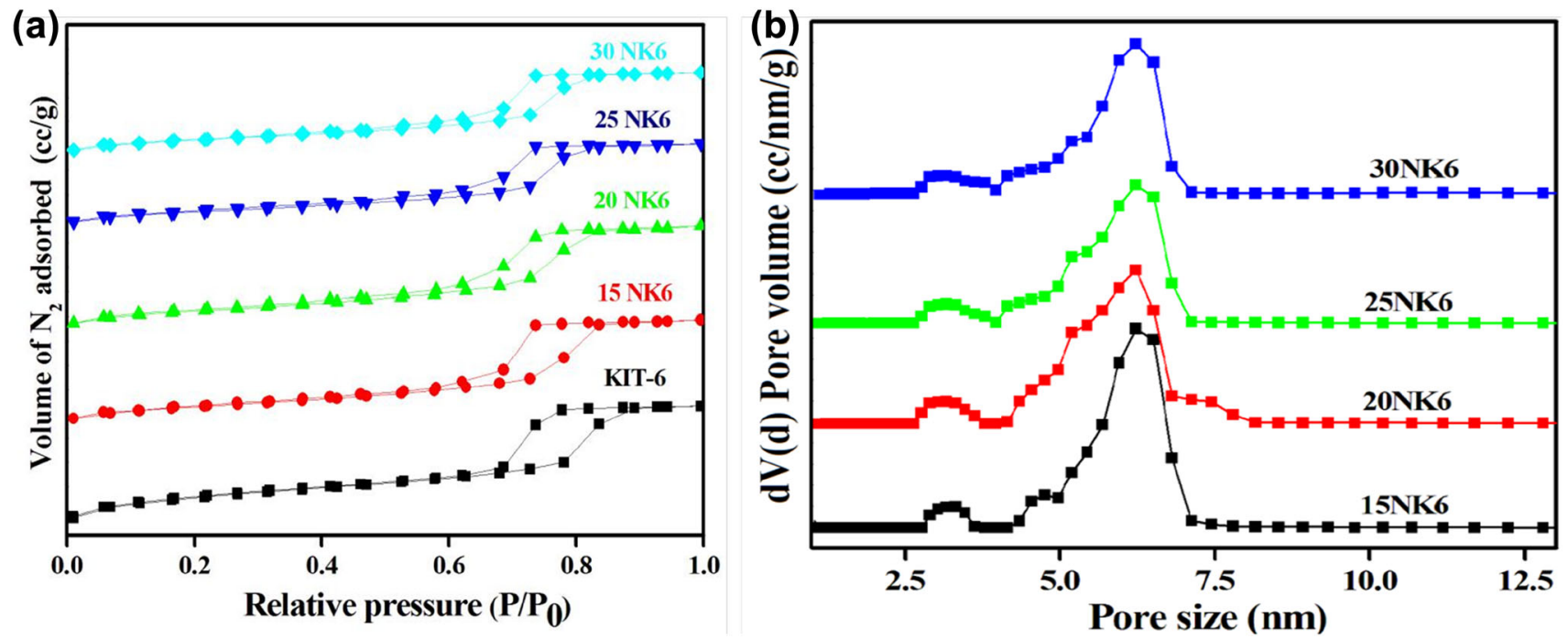

Figure 2. (a) $\mathrm{N}_{2}$ adsorption-desorption isotherms for parent KIT-6 and NK6 catalysts; (b) Pore Size distribution profiles of NK6 catalysts.

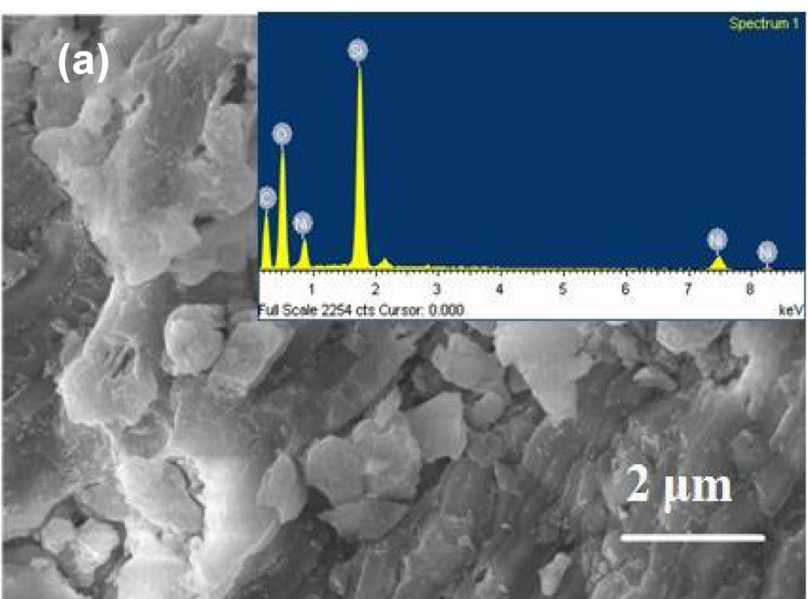

Figure 3. SEM and EDX images of (a) Fresh 20NK6 catalyst.

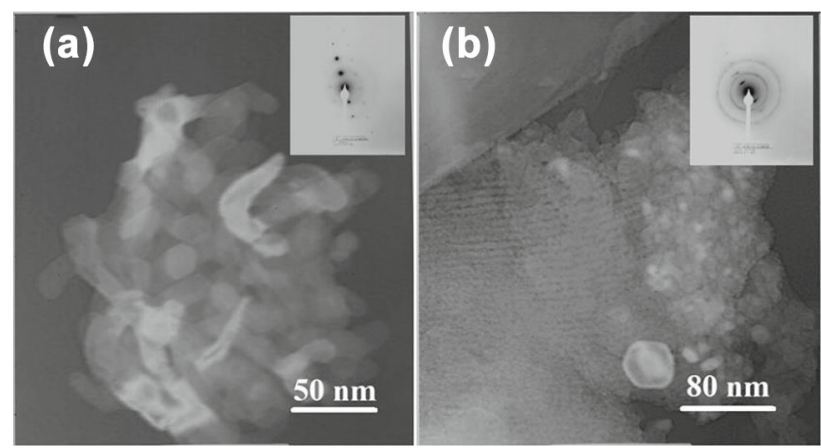

Figure 4. TEM images of (a) Fresh 20NK6 and (b) Spent 20NK6 catalysts.

catalyst, temperature programmed reduction (TPR) was performed and the results are depicted in Figure 5. All the NK6 samples show the single stage reduction

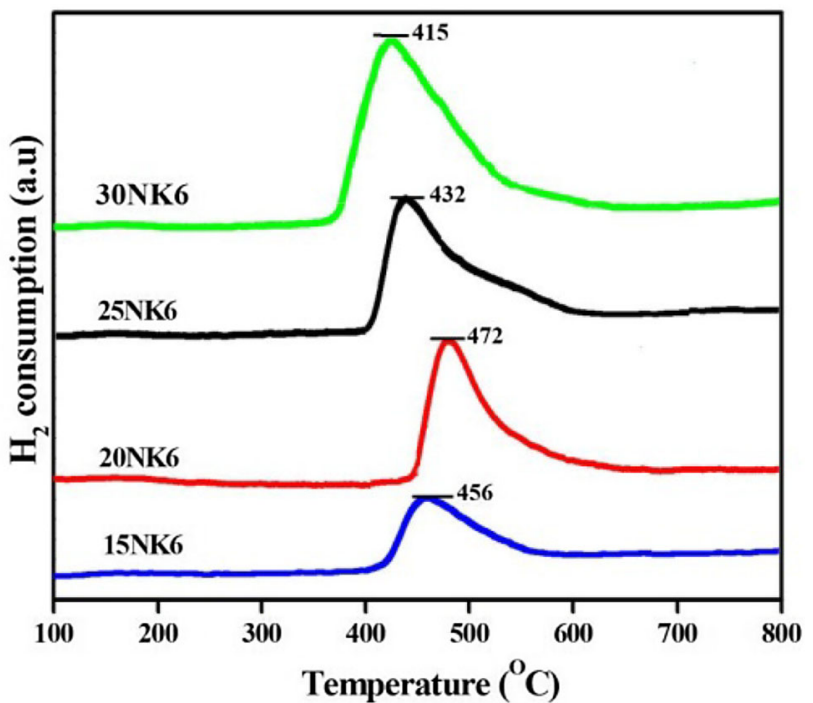

Figure 5. $\mathrm{H}_{2}-\mathrm{TPR}$ profiles of NK6 catalysts.

peak between $350-580^{\circ} \mathrm{C}$. It is well-known that nickel catalysts supported on silica showed different reduction patterns depending on the nature of the interaction between nickel oxide and mesoporous silica KIT-6 support. Bulk nickel oxide gets reduced at around $420{ }^{\circ} \mathrm{C}$. Among the catalysts, $20 \mathrm{NK} 6$ exhibit high $\mathrm{T}_{\max }$ value compared to other catalysts due to either strong interaction of nickel particles with the support, or due to the presence of uniformity in Ni particles over the support KIT- $6 . \mathrm{T}_{\max }$ of the catalysts follows the order, 20NK6 $>15$ NK6 $>25$ NK6 $>30$ NK6.

$\mathrm{H}_{2}$-pulse chemisorption studies were performed and the results are presented in Table 2. Among the Ni/KIT-6 
Table 2. $\mathrm{H}_{2}$ Chemisorption studies of NK6 catalysts.

\begin{tabular}{|c|c|c|c|c|}
\hline Catalyst & $\mathrm{H}_{2}$ uptake (m moles/g) & Metal surface area ${ }^{a}\left(\mathrm{~m}^{2} / \mathrm{g}\right.$ cat $)$ & $\mathrm{Ni}^{0}$ particle size ${ }^{\mathrm{b}}(\mathrm{nm})$ & Dispersion $^{\mathrm{c}}(\%$ \\
\hline 15NK6 & 82 & 6.5 & 15.4 & 6.4 \\
\hline 20NK6 & 90 & 7.2 & 18.6 & 5.3 \\
\hline 25NK6 & 78 & 6.2 & 26.8 & 3.7 \\
\hline 30NK6 & 75 & 6.0 & 33.5 & 2.9 \\
\hline
\end{tabular}

a,b,c Obtained from $\mathrm{H}_{2}$ uptake. ${ }^{\mathrm{a}}$ Active metal surface area $(\mathrm{ASA})=\mathrm{Nm} \times \mathrm{S} \times \mathrm{Am} \times 6.023 \times 10^{23}$; where ASA is in $\mathrm{m}^{2} / \mathrm{g}$ of the sample; $\mathrm{Nm}=$ the number of adsorbed gas molecules (Mole $\times 10^{-6} / \mathrm{g}$ ), $\mathrm{S}=$ adsorption stoichiometric, $\left(\mathrm{Ni} / \mathrm{H}_{2}=2\right), \mathrm{Am}=$ the cross-sectional area occupied by each active nickel surface atom $\left(6.623 \times 10^{-20} \mathrm{~m}^{2}\right),{ }^{\mathrm{b}}$ Average particle size $(\mathrm{d})=10 \times \mathrm{L} \times \mathrm{f} / \mathrm{ASA} \times \mathrm{Z}$; Where $\mathrm{L}=$ percentage nickel loading, $\mathrm{f}$ is a particle 'Shape correction factor' ( 6 for spherical particles), $Z=$ density of the nickel metal $\left(8.9 \mathrm{~g} / \mathrm{cm}^{3}\right), \mathrm{d}$ is in $\mathrm{nm} .{ }^{\mathrm{c}} \% \mathrm{Ni}$ Dispersion $(\mathrm{D})=\mathrm{Nm} \times \mathrm{S} \times \mathrm{M}$ /100xL; Where $\mathrm{M}$ is the molecular weight of nickel (58.7 g).

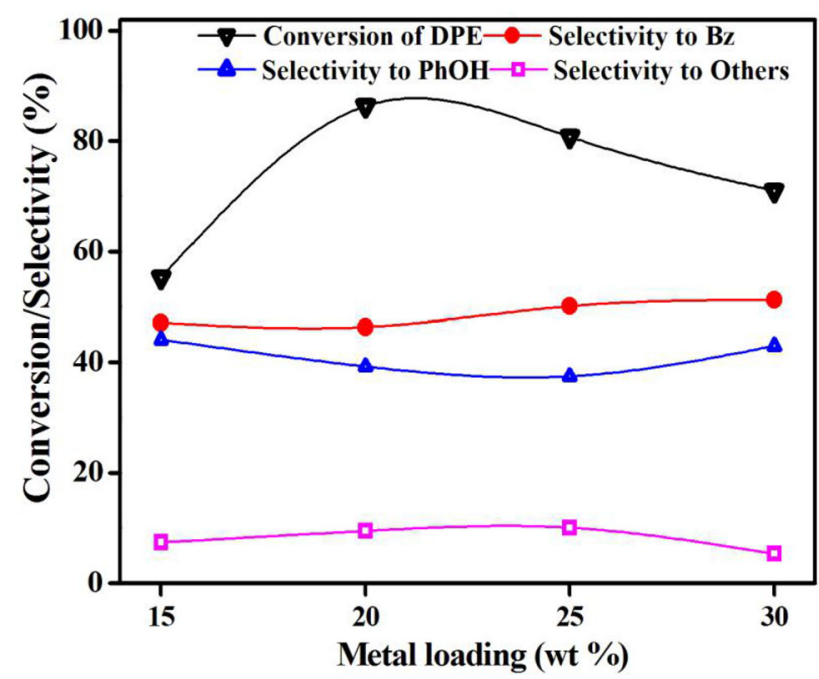

Figure 6. Influence of Nickel loading on the hydrogenolysis of DPE. Reaction conditions: catalyst: $1 \mathrm{~g}$, Reaction temperature: $275^{\circ} \mathrm{C}, \mathrm{H}_{2}$ flow: $20 \mathrm{~mL} \mathrm{~min}^{-1}$, liquid feed flow: $1 \mathrm{~mL} \mathrm{~h}^{-1}$.

catalysts, $20 \mathrm{NK} 6$ shows more $\mathrm{H}_{2}$ uptake and greater metal surface area than the other catalysts.

\subsection{Activity results}

In order to evaluate the optimum $\mathrm{Ni}$ loading, the hydrogenolysis of DPE is conducted over various NK6 catalysts and the results are presented in Figure 6. During the hydrogenolysis of DPE reaction, the possible products obtained are shown in Scheme 1.

Beyond $20 \mathrm{wt} \% \mathrm{Ni}$ loading, there is a decrease in the conversion of DPE due to the increase in the crystallite size of $\mathrm{Ni}$ atoms. In all the cases, the selectivity towards benzene and phenol is more or less same. Hence, 20NK6 is found to be the better one among the other catalysts. This is due to the 20NK6 catalyst that shows the maximum amount of $\mathrm{H}_{2}$ uptake, which also indicates an increased number of active sites and a greater active metal surface area than other catalysts.

The effect of temperature on the hydrogenolysis of DPE was carried out within the range of $275-350{ }^{\circ} \mathrm{C}$ over 20 NK6 and the results are presented in Figure 7. The conversion of DPE decreases gradually with a rise in temperature from 275 to $350{ }^{\circ} \mathrm{C}$ and reaches a minimum of $58 \%$ at $350{ }^{\circ} \mathrm{C}$. In addition, the selectivity towards phenol decreases, and benzene increases with the rise in temperature from 275 to $350{ }^{\circ} \mathrm{C}$. These results suggest that higher than $275^{\circ} \mathrm{C}$ of reaction temperature leads to a lower yield of aromatics.

The influence of $\mathrm{H}_{2}$ flow on the hydrogenolysis of DPE was studied over 20NK6 and the results are presented in Figure 8. There is an increase in the conversion of DPE from 59 to $86 \%$ with $\mathrm{H}_{2}$ flow from 15 to $20 \mathrm{~mL} / \mathrm{min}$ due to the increase in the number of available $\mathrm{H}_{2}$ molecules. A further increase in flow decreases the

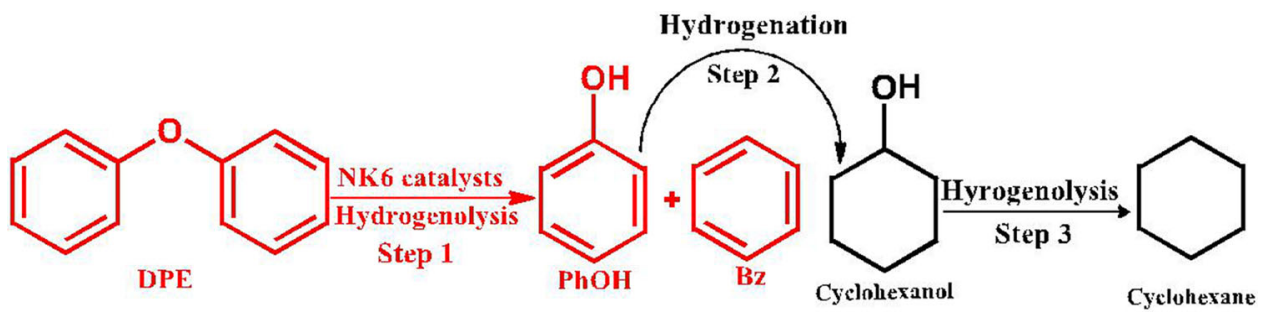

Scheme 1. Plausible reaction pathway for the hydrogenolysis of DPE over NK6 catalysts. 


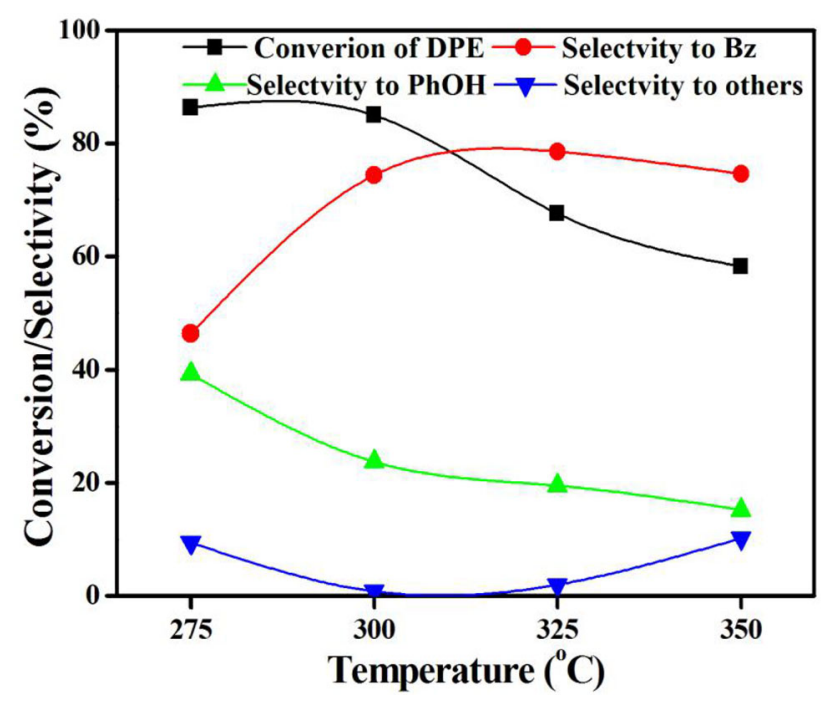

Figure 7. Influence of the reaction temperature on the hydrogenolysis of DPE. Reaction conditions: catalyst: $1 \mathrm{~g}$, $\mathrm{H}_{2}$ flow: $20 \mathrm{~mL} \mathrm{~min}^{-1}$, liquid feed flow: $1 \mathrm{~mL} \mathrm{~h}^{-1}$.

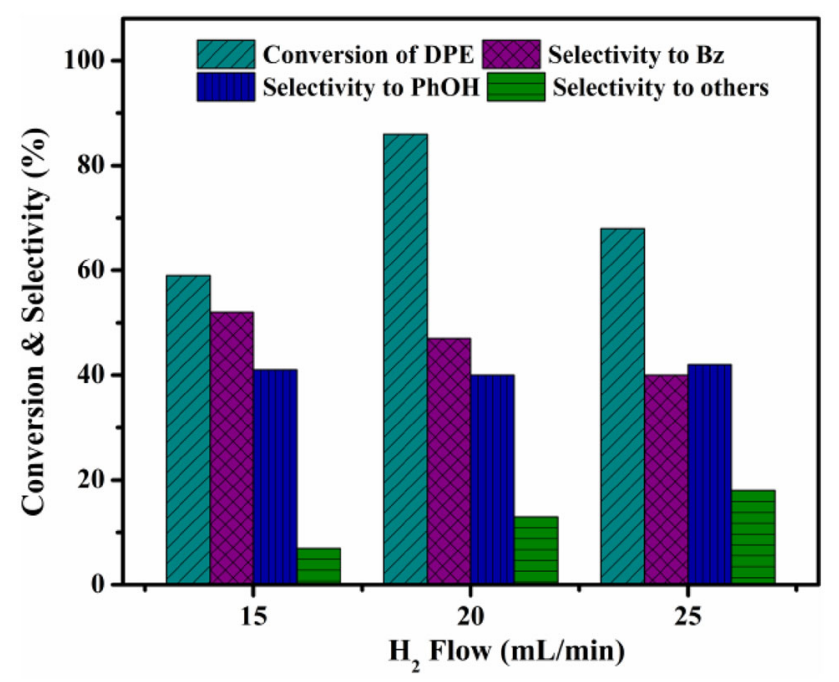

Figure 8. Effect of $\mathrm{H}_{2}$ flow on the hydrogenolysis of DPE. Reaction conditions: catalyst $\mathrm{t}$ : $1 \mathrm{~g}$, Reaction temperature: $275^{\circ} \mathrm{C}$, liquid feed flow: $1 \mathrm{~mL} \mathrm{~h}^{-1}$.

conversion of DPE due to the low contact time between reactants and catalyst.

The stability of 20NK6 was evaluated by performing time-on-stream studies under optimized reaction conditions and the results are presented in Figure 9. It can be observed that there was a decrease in the conversion of DPE but the selectivity towards benzene and phenol was almost stable during the $6 \mathrm{~h}$ time-on-stream studies. The reason for the decrease in the catalytic activity of the catalyst was due to the formation of coke over the surface of active sites of 20NK6 and it is confirmed by CHNS analysis. Moreover, there was no change in the structural features of the 20NK6 catalyst.

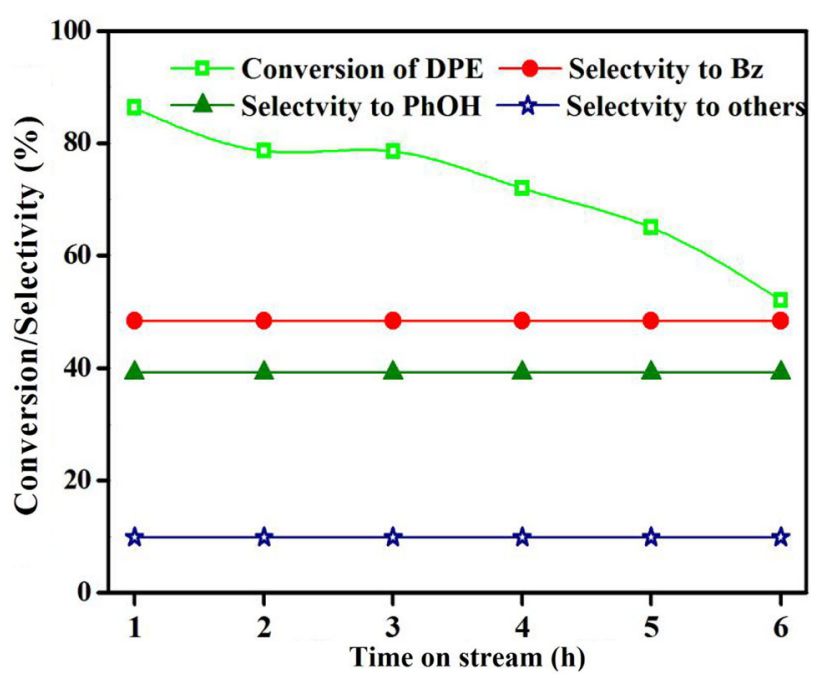

Figure 9. Time-on-stream study of 20NK6 catalyst on the hydrogenolysis of DPE. Reaction conditions: catalyst: $1 \mathrm{~g}$, Reaction temperature: $275^{\circ} \mathrm{C}, \mathrm{H}_{2}$ flow: $20 \mathrm{~mL} \mathrm{~min}^{-1}$, liquid feed flow: $1 \mathrm{~mL} \mathrm{~h}^{-1}$.

\section{Conclusions}

The mesoporous silica KIT-6 supported Ni catalysts were successfully prepared by the wet impregnation method. All the catalysts retained their mesoporous structure even after the highest amount of Ni deposition. Among the catalysts, 20Ni/KIT-6 was found to be the most effective one in the hydrogenolysis of DPE at atmospheric pressure in a continuous process. $20 \mathrm{Ni} / \mathrm{KIT}-6$ suffers from a decrease in the conversion of DPE due to the accumulation of coke over the active sites of the catalyst.

\section{Acknowledgements}

The authors J.V., K.K.S., S.S.E. and V.V. thank UGC, New Delhi for sponsoring the fellowships.

\section{References}

1. Zakzeski J, Bruijnincx P C A, Jongerius A L and Weckhuysen B M 2010 The catalytic valorization of lignin for the production of renewable chemicals Chem. Rev. 110 3552

2. Song W, Liu Y, Barath E, Zhao C and Lercher J A 2015 Synergistic effects of $\mathrm{Ni}$ and acid sites for hydrogenation and $\mathrm{C}-\mathrm{O}$ bond cleavage of substituted phenols Green Chem. 171204

3. Lu M, Zhu J, Li M, Shan Y, He M and Song C $2016 \mathrm{TiO}_{2}$ modified $\mathrm{Pd} / \mathrm{SiO}_{2}$ for catalytic hydrodeoxygenation of guaiacol Energy Fuels 306671

4. Parthasarathi R, Romero R A, Redondo A and Gnanakaran S 2011 Theoretical Study of the Remarkably Diverse Linkages in Lignin J. Phys. Chem. Lett. 2 2660 
5. Luo Y R 2007 Comprehensive handbook of chemical bond energies (Boca Raton, Boca Raton, FL: CRC Press

6. Nichols J M, Bishop L M, Bergman R G and Ellman J A 2010 Catalytic C-O bond cleavage of 2-aryloxy1-arylethanols and its application to the depolymerization of lignin-related polymers J. Am. Chem. Soc. 132 12554

7. Patil P T, Armbruster U, Richter M and Martin A 2011 Heterogeneously Catalyzed Hydro processing of Organosolv Lignin in Sub- and Supercritical Solvents Energy Fuels $\mathbf{2 5} 4713$

8. Runnebaum R C, Nimmanwudipong T, Block D E and Gates B C 2012 Catalytic conversion of compounds representative of lignin-derived bio-oils: a reaction network for guaiacol, anisole, 4-methylanisole, and cyclohexanone conversion catalysed by $\mathrm{Pt} / \gamma-\mathrm{Al}_{2} \mathrm{O}_{3}$ Catal. Sci. Technol. 2113

9. Harris E E, D'Ianni J and Adkins H 1938 Reaction of hardwood lignin with hydrogen J. Am. Chem. Soc. 60 1467

10. Jongerius A L, Jastrzebski R, Bruijnincx P C A and Weckhuysen B M 2012 CoMo sulfide-catalyzed hydrodeoxygenation of lignin model compounds: An extended reaction network for the conversion of monomeric and dimeric substrates J. Catal. 285315

11. Sergeev A G and Hartwig J F 2011 Selective nickelcatalyzed hydrogenolysis of aryl ethers Science 332439

12. Gao F, Webb J D and Hartwig J F 2016 Chemo- and regioselective hydrogenolysis of diaryl ether $\mathrm{C}-\mathrm{O}$ bonds by a robust heterogeneous $\mathrm{Ni} / \mathrm{C}$ catalyst: applications to the cleavage of complex lignin-related fragments Angew. Chem. 1281496
13. He J, Zhao C and Lercher J A 2012 Ni-catalyzed cleavage of aryl ethers in the aqueous phase J. Am. Chem. Soc. 134 20768

14. Jiayue He, Chen Zhao, Donghai Mei and Johannes Lercher A 2014 Mechanisms of selective cleavage of C$\mathrm{O}$ bonds in di-aryl ethers in aqueous phase J. Catal. 309 280

15. Wang X and Rinaldi R 2012 ChemSusChem 51

16. Enumula S S, Koppadi K S, Gurram V R B, Burri D R and Kamaraju S R R 2017 Conversion of furfuryl alcohol to alkyl levulinate fuel additives over $\mathrm{Al}_{2} \mathrm{O}_{3} / \mathrm{SBA}-15$ catalyst Sustain. Energy Fuels 1644

17. Enumula S S, Gurram V R B, Chada R R, Burri D R and Kamaraju S R R 2017 Clean synthesis of alkyl levulinates from levulinic acid over one pot synthesized WO3-SBA16 catalyst J. Mol. Catal. A $\mathbf{4 2 6} 30$

18. Kim T W, Kleitz F, Paul B and Ryoo R 2005 MCM-48like large mesoporous silicas with tailored pore structure: facile synthesis domain in a ternary triblock CopolymerButanol-Water system J. Am. Chem. Soc. 1277601

19. Oveisi H, Anand C, Mano A, Al Deyab S S, Kalita P, Beitollahi A and Vinu A 2010 Inclusion of size controlled gallium oxidenanoparticles into highly ordered 3D mesoporous silica with tunable pore diameters and their unusual catalytic performance J. Mater. Chem. 20 10120

20. Siva Sankar E, Saidulu Reddy K, Jyothi Y, David Raju B and Seetha Rama Rao K 2017 Alcoholysis of furfuryl alcohol into $n$-butyl levulinate over SBA-16 supported heteropoly acid catalyst Catal. Lett. 1472807

21. Soni K, Rana B S and Sinha A K 2009 3-D ordered mesoporous KIT-6 support for effective hydrodesulfurization catalysts Appl. Catal. B Environ. 9055 